\title{
Practical Problems and Obstacles to Inflation Targeting
}

\author{
Laurence H. Meyer
}

T he number of conferences, papers, and speeches on inflation targeting suggests a growing interest in exploring whether and in what way the Federal Open Market Committee (FOMC) should consider adopting an explicit numerical objective for inflation. Because the devil is often in the details, it is important to go beyond the general interest in this direction and to explore obstacles to moving in the direction and, at the same time, to begin to think about some practical problems that would have to be resolved if such an approach were to be implemented.

My point of departure is the conviction that, if the FOMC were to adopt an explicit numerical inflation target, the vision of the resulting regime would have to fit both the political realities and the basic approach to monetary policymaking in the United States over the past decade. Indeed, the case for adopting an explicit inflation target in the United States is typically rationalized in terms of continuity rather than change. That is, it is an attempt to ensure continuity in the conduct of monetary policy, especially after the departure of Alan Greenspan, not to be an instrument for changing the way in which monetary policy has been conducted over the past decade or two.

The key distinction essential for understanding the regime that would be a good fit for the United States is between inflation targets and inflation targeting. After explaining that distinction, I will offer my view of the vision of the Greenspan FOMC and consider the consistency of that vision with a regime with an explicit numerical inflation target. Next I consider the political climate for adopting an inflation target and other potential obstacles. I will conclude with a consideration of implementation details, as the choice is not ultimately between an explicit and implicit target in principle, but between the current practice and a specific alternative.

\section{INFLATION TARGETS AND INFLATION TARGETING}

This distinction between inflation targets and inflation targeting, first made in a speech in July 2001 while I was a member of the Board of Governors, can perhaps be best understood in terms of a two-bytwo matrix (Table 1). Across the top, I identify two types of inflation targets, one implicit (like the United States today) and the other explicit (as in socalled "inflation targeting" countries today). Down the side I identify two forms of mandate that central banks around the world operate under. These mandates are typically set by the legislatures. The United States and Australia operate under a dual mandate, according to which monetary policy is directed at promoting both full employment and price stability, with no priority expressed, and with the central bank responsible for balancing these objectives in the short run. Inflation-targeting countries generally operate under hierarchical mandates, one in which price stability is identified as the principal objective, and central banks are restricted in pursuing other objectives unless price stability has been achieved.

The United States has an implicit inflation target and a dual mandate, the upper left. The United Kingdom, Canada, and other so-called inflationtargeting countries have an explicit inflation target and a hierarchical mandate. They are in the lower right. Australia has a dual mandate along with an explicit inflation target. That is the combination I am suggesting for the United States.

Lars Svensson always responds to my proposal by telling me that my distinction between dual and hierarchical mandates is too strict. In particular it misses the evolution in practice around the world. In general, inflation-targeting countries today have moved away from the initially austere implementation, more in line with the spirit of a hierarchical mandate, and have become flexible inflation targeters, close cousins of dual mandate central banks.

Laurence H. Meyer is a distinguished scholar at the Center for Strategic and International Studies and president of Meyer's Monetary Policy Insights.

Federal Reserve Bank of St. Louis Review, July/August 2004, 86(4), pp. 151-60

(C) 2004, The Federal Reserve Bank of St. Louis. 
Table 1

\section{Monetary Policy Regimes}

\begin{tabular}{lcc} 
& \multicolumn{2}{c}{ Inflation target } \\
\cline { 2 - 3 } Mandate & Implicit & Explicit \\
\hline Dual & U.S. & Australia \\
Hierarchical & & U.K., Canada \\
\hline
\end{tabular}

There are two possibilities in connection with that evolution. First, the language in the mandates was intended to impose restrictions on the central banks, restrictions that went beyond simply identifying an explicit numerical inflation objective. So, whatever you want to call inflation targeters, from nutters to flexible inflation targeters, central banks under a hierarchical mandate are going to behave differently, specifically with less flexibility than in the case of dual mandate central banks. It is of course a topic for research, as to whether or not such differences can be identified in practice.

Second, what about the assessment that there is no practical difference between flexible inflation targeters operating under a hierarchical mandate and dual mandate central banks? If this were the case, the only difference between dual and hierarchical mandate central banks is one of transparency. Dual mandate central banks are transparent about their objectives and flexible inflation targeters are not. To allow for this possibility, I have shown a second two-by-two matrix, what I call my Lars Svensson model.

The transparency with respect to the stabilization objective for monetary policy is itself a fascinating subject. Historically, central bankers, unlike members of the Congress, have been embarrassed to admit they care about anything other than price stability or conduct monetary policy for any other purpose. Bob McTeer has perhaps said it best when he reminded the Committee that "only hawks go to central bank heaven." Even in the United States, it is much easier to find quotes from FOMC members about the importance of price stability than about the responsibility of monetary policymakers for damping fluctuations in output around full employment. You all, I expect, recall the pillorying Alan Blinder received when he noted at the Jackson Hole conference in August 1994 that monetary policymakers should keep an eye on the unemployment rate as well as on inflation.
This also reminds me of an incident at my very first Jackson Hole conference as a member of the Board in August 1996. Two of the leading central bankers in the world took me aside to help educate me about how to conduct myself so I would be viewed as an upstanding central bank citizen. They offered me the very same advice. Good central bankers never admit they pursue stabilization policy. Such an admission would reduce the confidence of the public in your commitment to price stability and therefore undermine your credibility and effectiveness as a monetary policymaker. I responded that I appreciated the advice, especially from such distinguished central bankers, but that it left me a bit confused. They seemed to be telling me that the way to build credibility was to lie, specifically about how I understood the objectives and how I intended to conduct monetary policy. I never followed their advice and indeed tried to educate the public about the importance of the dual mandate.

This distinction between dual and hierarchical mandates is central to the issue of the obstacles to moving to an explicit numerical inflation target in the United States and to the goal of designing a regime that provides for continuity with the vision of monetary policy as practiced in the United States for at least the past decade or two. Indeed, many of those who vigorously oppose inflation targets do so because they identify that practice with the hierarchical mandates and a down-weighting of responsibility of the central bank for promoting full employment.

One caveat is in order here. There are important differences between the full employment and price stability objectives, and I do not want to minimize or disregard these differences, because they are central to good practice for central banks. These differences may indeed be the origin for hierarchical mandates, though I expect the origin has more to do with the disappointing experience with monetary policy and inflation before the inflation-targeting regimes were adopted.

First, a central bank, over some appropriate intermediate term, can achieve an inflation target, with a significant degree of precision. It has a choice as to whether that target should be 2 percent or 3 percent or some other number. In a word, with respect to inflation, the buck literally does stop at the central bank. Central banks have less influence over the short-run path of output and employment, but, nevertheless, at the margin, can damp movements in output around its potential level. 
Second, with respect to an inflation target, central banks know where they want to go. Notwithstanding biases and measurement issues, the central bank can pick a target and get there. Unfortunately, the same cannot be said for the full employment objective. We do not know exactly where it is at a given moment or where it may be in the future. It is, of course, not really as murky as that characterization suggests, but we have only an estimate of the nonaccelerating inflation rate of unemployment (NAIRU) and of potential output, and we have to update that estimate over time, in part using information based on the experience with inflation. This measurement uncertainty does not mean that a central bank should not pursue its estimate of full employment, but it does imply that that pursuit has to be different in some subtle ways from the way it pursues its inflation objective. In particular, central banks cannot simply aim for a particular unemployment rate and decide after the fact if it is really sustainable. Rather, monetary policymakers have to be prepared to move aggressively into the range of the estimate of full employment and then perhaps move more gingerly toward the estimate, watching each step along the way for feedback as to whether it has gone far enough or has overshot.

\section{THE VISION OF GREENSPAN}

My premise is that the goal of any change with respect to the inflation target is one designed to preserve and even ensure continuity in the way monetary policy has been conducted under the Greenspan FOMC. I therefore set out my vision of that approach, identifying the three principles that, in my view, have guided practice.

\section{Build a reputation for a commitment to} price stability in order to anchor inflation expectations. While an inflation target can in principle contribute to this end, inflation expectations, in practice, are based more on performance than promise. Hence, outcomes are more important than rhetoric. Therefore, the first principle is that monetary policy should be conducted to move the inflation rate over time to a low, stable rate (the FOMC's implicit inflation target) and then to maintain it close to that rate, with allowances for normal cyclical variation. I thus identify the FOMC under Greenspan as an implicit inflation targeter.

2. Monetary policymakers should aggressively respond to demand shocks that would otherwise move output and employment from their full employment levels, with appropriate consideration for prevailing and prospective inflation rates. Wellanchored inflation expectations provide monetary policymakers increased freedom to adjust policy in the shorter run to damp movements in output relative to potential, without concern that such aggressive use of stabilization policy could destabilize inflation expectations. There is a corollary to the second principle. The anchoring of inflation expectations itself makes the economy more stable, reducing the effect on overall inflation of adverse supply shocks and reducing the instability that arises when the economy is allowed to overheat and inflation rises above the implicit inflation target, to be reversed later on.

3. Monetary policymakers should be flexible and pragmatic in the conduct of monetary policy. Policy rules can provide useful guidance to monetary policymakers, but policymakers' judgment will be essential in responding to unique shocks or circumstances and to making policy when the uncertainty about the model, parameters, or the measurement of key variables becomes especially large.

The Chairman, in my view, also believes that low, stable inflation contributes to strong productivity growth and hence to a higher maximum sustainable rate of economic growth. This provides still another reason why maintaining low stable inflation has significant payoffs for economic performance. I expect that the other members of the FOMC have less faith in this principle than the Chairman.

What is unique about the Greenspan vision are the synergies presumed between the two objectives for monetary policy - price stability and damping fluctuations around full employment-as well as between price stability and achieving maximum sustainable growth. What is also unique is that the Chairman, based on this vision, is generally viewed as being a hawk when it comes to containing inflation and a dove when it comes to quickly providing support for a weakening economy. That is a remarkable combination, politically as well as economically, and one that the FOMC presumably would not want to lose as it considers adopting an explicit numerical target for inflation. 


\section{THE POLITICS OF INFLATION TARGETS}

The Congress sets the objectives for monetary policy, just as legislatures typically do in the case of other central banks around the world. The Greenspan vision, if not rhetoric, is, in my view, very much in sync with the Congressional mandate.

There is, in my opinion, no chance that the Congress would accept a regime with a hierarchical mandate that raised the profile of price stability and diminished the responsibility of the FOMC for stabilization policy. It is true that there have been specific bills introduced in the Congress that would have moved the Fed in this direction. But those bills reflected a minority position, indeed a very small minority position, and the overwhelming majority of the Congress would have rejected such an approach. The only exception would be if there was a period in which monetary policy in the United States was not appropriately disciplined and inflation rose to very high levels. The Congress might then impose a more restrictive mandate. And that is the historical experience that preceded the implementation of many of the inflation-targeting regimes around the world.

Nevertheless, there could be an obstacle in achieving a consensus with the Congress about any change in the conduct of monetary policy. The greater danger is that the Congress would want to balance an explicit target for inflation with an explicit target for full employment. And, for the reasons developed above-specifically, we do not know precisely the level of the NAIRU or potential output, and our estimates of these indicators of full employment change over time-the FOMC could not accept an explicit numerical target for inflation if it were bundled with an explicit target for full employment. This is perhaps the most important reason why consultations with the Congress are so important as a part of any interest of the FOMC in moving in this direction. My belief is that the Congress would accept an explicit numerical target for inflation in the context of a reaffirmation of the Federal Reserve's responsibility for promoting full employment.

So both the political realities and the focus on continuity require that an explicit numerical target for inflation be implemented as part of a dual mandate and be done in a way that does not undermine the flexibility of monetary policy to respond to various shocks or unusual circumstances. This is both the only choice and the best direction.

\section{WHY BOTHER?}

The FOMC is already an implicit inflation targeter; and policy has been successful in achieving a low rate of inflation, while preserving flexibility to pursue stabilization policy. As a result, there is some understandable skepticism about the payoff in terms of better policy or improved outcomes from making the inflation target explicit.

First, at the margin, an explicit inflation target should contribute to anchoring inflation expectations, both by identifying the point at which the public should put down the anchor and by establishing a consensus on the Committee about where the anchor should be. I personally believe that an explicit inflation target is more effective in anchoring inflation expectations once the target has already been achieved, rather than in lowering the cost of initially achieving the target.

Second, an explicit inflation target would also ensure a consensus on the Committee about the inflation rate members should be aiming at, ensuring that everyone is pushing in the same direction with respect to the inflation objective. This could, at the margin, improve the coherence of the deliberations and the policy outcomes. It should be noted, however, that the payoff from more coherent internal deliberations could be achieved by having an internally acknowledged target and does not require that the target be made public. However, in my view, it would be difficult to sustain and inappropriate politically for the Committee to agree on a target internally and not announce it publicly.

Third, the added transparency about monetary policy might further enhance the ability of bond market participants to anticipate the future course of monetary policy, shortening the lags from policy to outcomes, and thereby improving the effectiveness of policy. There is, I believe, a synergy between transparency and policy effectiveness; and, if so, the adoption of an explicit numerical inflation target will be a step toward a more effective monetary policy, improving the partnering between monetary policy and the bond market.

\section{PROCESS}

Part of the successful navigation through the political process is to set up a well-structured process of inside deliberation, outside consultation, and Congressional oversight about both the general direction and the details of the implementation. The degree of acceptance of the direction will ultimately 
depend importantly on the details, including the reaffirmation of the commitment to the dual mandate, the precise level of the target, whether there is a range or just a point, the timeframe over which the FOMC would be judged about its compliance with the target, and any reporting requirements that accompanied the new regime.

Below, I set out a possible process for moving toward an explicit numerical inflation target in the United States.

1. The process should begin with internal discussion. There has to be, at the outset, sufficient support within the FOMC to justify a renewed and intensified focus on the topic. The FOMC then has to direct the staff to develop options and implementation details.

2. The staff should then revisit some of the topics they have previously considered, update some of the previous relevant studies, including the work presented at the July 1996 and July 1997 FOMC meetings, and set out options for implementation details.

3. The FOMC should then make a decision as to whether they want to adopt an explicit inflation target and set out a preliminary proposal for implementation details.

4. At this point, the Chairman should brief Congressional leaders about the desire of the FOMC to move in this direction and set up a mutually agreed consultation process, including hearings. An agreement would be reached as to whether the inflation target was to be adopted by the FOMC, in pursuance of the existing Congressional mandate for price stability, or whether the target was subject to consideration and approval by the Congress.

5. The preliminary proposal should be released to the public for comments.

6. After comments, a final proposal would be released and, after further Congressional consultations and perhaps hearings, would be implemented.

\section{OBSTACLES}

The most obvious obstacle to establishing an explicit numerical target for inflation is, of course, Alan Greenspan. He has made it clear that he is opposed to moving in this direction, though the argument he made at a conference at this Bankspecifically that he opposed an explicit target for inflation because we could not measure inflation precisely enough - was singularly disappointing and uncompelling. No matter. The Chairman clearly prefers the status quo for the remainder of his term, and no one on the Committee, including myself when I was there, would push to adopt an explicit inflation target while he was at the helm. But when the Chairman's term is over in early 2006, the topic will likely resurface and become an active one inside and outside the FOMC.

The second obstacle could be the new chairman. The new chairman should presumably be given some time to develop his own views on the topic and will undoubtedly have a considerable influence on whether the Committee moves in this direction. On the other hand, I expect the Committee will be looking to assert greater influence on policy outcomes and directions for policy strategy, and the momentum inside the Committee to at least give this careful consideration is likely to be impossible to contain.

The third obstacle is the politics of inflation targeting. The irony is that it might take a chairman with the clout and political savvy of Alan Greenspan to navigate such a change through the political process. I believe that the current legislative mandate provides a legal basis for the Fed to adopt a numerical inflation target, as long as the FOMC continues to accept the dual mandate. Nevertheless, adopting an inflation target would be viewed as an important change in the monetary policy regime and, as such, would need to be vetted with the oversight committees in the Congress. While I do not believe that new legislation is needed, the Fed would have to ensure that the Congress was comfortable with this direction.

The fourth is inertia. Members of the FOMC undoubtedly believe, as I do, that the Committee has conducted policy in a flexible yet disciplined and effective manner over the past decade. There is no perceived imperative to change the policy regime. It could be argued that adopting a numerical inflation target is not fundamentally a change in the regime, but the point is still "if it ain't broke, why fix it."

The fifth obstacle is the challenge of building a consensus for the change inside the FOMC and then for the details of the change. To do so, it will be necessary to meet head on the legitimate concerns of some who have staked out positions against such a direction. By the way, my basic procedural proposal is to lock Governors Ben Bernanke and Don Kohn in a room and not let them out until they have 
reached an agreement. That agreement is one I am sure I and the overwhelming majority of the Committee likely could accept.

What is the core of the case against an inflation target? Don Kohn, in my view, has presented the most thoughtful argument against moving in this direction. There may be a trade-off between becoming more transparent and accountable by adopting an explicit numerical inflation target and losing some of the flexibility that the Committee has had in the conduct of monetary policy.

My proposal-adopting an explicit numerical inflation target in the context of a reaffirmation of the Committee's commitment to the dual mandateis designed to meet that concern by making clear that the intention of the change was not to alter the way in which monetary policy has been conducted, but only to make that conduct more transparent and accountable.

Still, that concern lingers. It can perhaps be appreciated in terms of the Taylor rule, viewed as a simple summary of the way in which the FOMC conducts monetary policy. The question then is whether the FOMC can make explicit the numerical target for the inflation objective-one of the key terms on the Taylor rule-without, at the same time, also altering the response coefficient on the output gap relative to the response coefficient on the gap between inflation and the inflation target. That is, can the Committee more precisely identify one target without changing the way it balances its two objectives and the aggressiveness, in particular, with which it responds to deviations in inflation from its target?

Perhaps even more to the point, does adopting an explicit and numerical inflation target force monetary policymakers to be more mechanical in their conduct of monetary policy, as in following more closely a Taylor rule, as opposed to having the flexibility to deviate from the rule when circumstances encourage the Committee to do so?

I would not argue that this is a trivial question and one without merit. Indeed, many who favor an inflation target or a full-fledged inflation-targeting regime do so precisely because such an approach constrains discretion. It is noteworthy that in their discussions of the policy framework, Governor Bernanke's highest praise goes to one which involves "constrained discretion," while Governor Kohn reserves his highest praise for a policy that is flexible and pragmatic. Of course, they both undoubtedly see the merit in the attempt to achieve a balance among these properties of a policy regime.
I do not believe that, under my proposal, there would be much risk that monetary policy would lose its current flexibility - but that would depend on how the change was understood by the Committee, the Congress, and the public. My recent experience reinforces this point. I have recently talked to economists who often say that they oppose moving to an inflation-targeting regime; when they heard my proposal, however, they not only indicated that they could support it but seemed at least modestly enthusiastic about going in that direction. That suggests that much of the opposition to an explicit numerical inflation target is really opposition to the hierarchical mandates and perceived practices of so-called inflation-targeting regimes.

In any case, I believe that the Committee would have to become comfortable that they could conduct policy with the degree of flexibility they have in recent years, while still adopting an explicit numerical inflation target.

The last obstacle to adopting an inflation target is agreeing upon the details. As it is often said, the devil is in the details. Even those who might support some version of an inflation target might not be able to agree on the details of such a regime. That provides a good bridge to my last section, practical problems with implementing an inflation target.

\section{PRACTICAL CONSIDERATIONS}

I presume that the staff would be asked to come up with some recommendations and perhaps options for the various implementation details required to develop a proposal for the adoption of an explicit numerical inflation target. I will offer my own views on how the various issues might be resolved, identifying some potential deal busters, but I would quite likely change my mind about some of the details after reading the staff's recommendations and hearing the comments both from members of the Committee and outsiders who have been focused on this topic.

\section{What Price Index Should the Inflation Target Be Based Upon?}

I do not believe there is a definitive answer to this question, but I also do not believe that the answer is very important, assuming the choice is between a broad production-based index, such as the chain-weighted price index for gross domestic product, or a broad-based consumption measure, such as the consumer price index (CPI) or the personal consumption expenditures (PCE). 
I do not believe that economic theory establishes whether a production- or a consumption-based measure of inflation is better as a target. Empirical analysis might reveal interesting differences in the way that monetary policy would respond to shocks under production- and consumption-based measures, and that analysis might help to make the decision. For example, the response of monetary policy to changes in the price of oil would be more aggressive under a consumption-based measure, although that conclusion would be reversed if the target was expressed in terms of a core measure of consumer price inflation.

Still, I expect, as with all other countries that have an inflation target, the choice will be a consumptionbased measure, as these appear more widely understood by the public. This is also the direction of the discussion of this topic at FOMC meetings, specifically in July 1996.

This would leave us with a choice between the CPI and PCE measures. I viewed this as a close call up until the release of the chain version of the CPI. The chain CPI inflation rate lined up much closer to, and indeed very close to, the PCE measure. I would therefore opt for the PCE measure. But I wouldn't be a fanatic about this choice. There are times when I might, were I a member of the FOMC, indicate that the Committee was putting somewhat more attention on the CPI measure, as a result of distortions believed to be affecting the PCE relative to the CPI.

\section{Should the Target Be Defined as Applying Over a Specified Time Horizon?}

The Congress and the public, as well as the FOMC itself, are going to want to monitor the success of the FOMC in achieving the target established for inflation.

First, the Committee should always refer to inflation in terms of the 12-month inflation rate for the measure it selects, and specifically not talk about monthly or even quarterly inflation rates. All monitoring of FOMC performance relative to the target should be focused on the 12-month rate.

Second, the Committee should emphasize that it is focused on achieving the target over an intermediate term and will move only gradually to return inflation to the target if a shock pushes inflation away from the target, especially if it is pushed outside its monitoring range.

Many inflation-targeting countries explicitly interpret their inflation target as applying to the intermediate term, typically out $1^{1 / 2}$ to 2 years. This is sometimes referred to as inflation-forecast targeting. Central banks often report their inflation forecast over this horizon, and it is expected that such forecasts will be lined up on the inflation target.

This approach creates a potential tension with a dual mandate. Under such a regime, it is not appropriate to always be at the inflation target, just as it would not be appropriate to always be at the point of maximum sustainable employment. An example would be that it would make sense for inflation to be above the inflation target late in the expansion. If inflation just rose to the target during expansions and fell below the target in recessions, the average inflation rate will be below the target. In addition, the overall target might have to be set higher in this case, to reduce the prospect of occasionally hitting the zero nominal bound.

In my view, a good way to set the target would be as an average over the business cycle. Of course, taken literally, that would be an average inflation target, with properties like a price level target, in that past deviations from the inflation target would not be forgiven, but might at least implicitly be expected to be offset by deviations in the other direction later.

\section{Should the Target Be the Overall Measure of Inflation or a Core Measure of Inflation?}

If the objective is viewed as the forecast for inflation over the intermediate term, say $1^{1 / 2}$ to 2 years out, then it does not matter very much, if at all, whether the target is specified as overall or core inflation. That is because any shock will have dissipated by then, so the policy that would be consistent with achieved overall and core inflation rates 2 years out would be very close, if not identical.

Still, the public and the Committee are going to want to monitor inflation outcomes along the way to determine whether the inflation performance is broadly consistent with the target. In my judgment, the core measure, by providing the best guidance about expectations for overall and core inflation in the future, is the better measure for monitoring how the FOMC is doing relative to its inflation target. I would prefer to use a core measure as the inflation target itself because I believe that would reduce possible confusion about how the Committee views departures from the inflation target induced by temporary supply shocks.

Still, the choice between core and overall meas- 
ures of inflation would make a difference in the conduct of monetary policy, at least if policymakers were responding to recent changes in inflation in their decisions about the setting of the funds rate target. As a result, the optimal response to price shocks remains an important consideration in the choice between core and overall inflation rates as targets. If it is optimal to "look through" the direct effects of a price shock, and only respond to the extent that there are indirect effects that later raise the core inflation rate, this might suggest a preference for the core measure. On the other hand, the presumption that some portion of a price shock would likely pass-through to the core may suggest the desirability of some initial response to the direct effect.

\section{Should the Target Be Set as a Point or a Range, and, if a Range, Should There Be a Special Focus on the Midpoint?}

I prefer either a point target or a range with a focus in the midpoint as the explicit target. This would likely provide a better anchor for inflation expectations and reduce the indecision in the markets when the central bank was at one end of the range about whether or not the central bank would look for an opportunity to move back to the middle.

That does leave the question of what the purpose of a range is and how wide the range should be. One purpose is to identify a range of variation that is typical cyclically and would not be as strongly resisted as when inflation moves outside the range. That suggests a kind of nonlinear policy response that could, in turn, be effective in limiting the variation of inflation expectations. The range might also identify, for example, the upper limit to where the Committee would be comfortable pursuing an opportunistic disinflation strategy, and the lower limit could identify the level below which policy would be more focused on erring on the side of ease, because of concerns about the possibility of deflation or hitting the zero nominal bound.

Many inflation-targeting countries have chosen a range of 1 percentage point, typically from 1 percent to 3 percent. Governor Bernanke has indicated that he would like to see inflation within a 1 percentage-point range, 1 percent to 2 percent.

\section{Should the Inflation Target Be Set Once and for All or Be Subject to Adjustment?}

The spirit of an inflation target is that it should be set and remain in place for long periods, so as to ensure economic agents that they can make longerrun decisions with confidence about the average inflation rate over such horizons.

But, while the target should not be changed often, there should be a willingness to revisit the target, on occasion, as evidence about the inflation bias evolves and as research provides new information about the appropriate size of the cushion relative to zero true inflation.

\section{Should the Target Be a Price Level or Inflation Target?}

There has been considerable discussion about the benefits of a price level rule for an economy facing the danger of deflation. Similar benefits accrue to a target for the average inflation rate over some period, as long as there is a commitment to compensating for periods when inflation is below the target with periods where inflation is above the target. However, as I have suggested, the case for moving to an explicit numerical inflation target is generally perceived to be an attempt to preserve continuity in U.S. monetary policy, not to provide an opportunity for a significant change in the way in which that policy is conducted. So I would not anticipate that an option of a price level target would be seriously considered.

\section{Should the Inflation Target Be Set for True Price Stability or Price Stability Plus a Cushion, and, if There Should Be a Cushion, How Large Should It Be?}

The FOMC considered this topic in considerable detail at the first FOMC meeting I participated in, in July 1996. Janet Yellen made the case for an inflation target set high enough to both take into account measurement error and also allow a cushion that took into account the potential deterioration in economic performance if inflation were too low.

She called for an inflation target of 2 percent and everyone on the Committee lined up to state their preference. The Chairman tried to get away with his vague definition of price stability: "Price stability is that state in which expected changes in the general price level do not effectively alter business or household decisions." But Yellen pressed him and asked if he could put a number on that. Remarkably, the Chairman agreed, and said he preferred zero inflation, correctly measured. Janet asked if he could settle for 2 percent incorrectly measured.

By the way, this is the only time during my $5^{1 / 2}$ years on the Board and the FOMC that anyone was able to extract from the Chairman a number related 
to his forecast, his estimate of productivity growth or anything else - of course, other than his recommendation each meeting for the federal funds rate target.

During a go-around on the topic, only a few Committee members preferred a target of zero, and the consensus was very strong for a 2 percent inflation target. The Chairman ended up summarizing the discussion as "an agreement for $2 \%$," but then cautioned Committee members not to reveal that such a discussion even took place.

Interestingly, the Chairman asked toward the end of the discussion to what measure of inflation the 2 percent target should apply. Yellen indicated she did not have a specific measure in mind, but most of the Committee appeared to be thinking in terms of the CPI, specifically the core CPI. Greenspan argued that the PCE was the better measure of consumer price inflation and that the target should be set in terms of the best measure. He then pointed out that while the core CPI was $2^{1 / 2}$ percent, the core PCE was already 2 percent, so that the Committee could apparently declare victory.

Bob McTeer noted, however, that the specific target depends on the specific measure. If the Committee preferred 2 percent for the core CPI, the consistent target for the core PCE would be $1^{1 / 2}$ percent, given the recent differentials among the measures. Interestingly, the Chairman's apparent acquiescence to a 2 percent target for the core PCE would have left him with a higher target for inflation than preferred by the rest of the Committee.

What if that discussion were opened up today? Governor Bernanke has indicated his preference for a target of 1 to 2 percent, presumably for the PCE measure, in line with the spirit of the July 1996 meeting. But a lot has happened since then, particularly experience in Japan with deflation and in the United States with low inflation.

The lessons drawn from these experiences have reinforced the wisdom of Yellen's remarks in July 1996, specifically that inflation can be too low as well as too high, and that monetary policymakers need to raise inflation to its target when inflation falls below the target, just as they need to lower inflation when it rises above the target.

Indeed, the lessons from recent experience suggest that policy should be asymmetric, in light of the asymmetric risks associated with deflation and the zero nominal bound. That is, policymakers should be more aggressive raising inflation to its target when it is initially too low than lowering it to its target when it is initially too high.
An interesting question is whether the inflation target should be set high enough so that policymakers could respond symmetrically to movements in inflation above and below the target, except perhaps in a small percentage of cases.

That suggests that consideration might be given, for example, to a $1^{1 / 2}$ percent or 2 percent target for the core PCE.

\section{Should Additional Reporting Require- ments Accompany the Introduction of an Explicit Numerical Inflation Target?}

A feature of inflation-targeting regimes, in additional to an explicit numerical inflation target and a hierarchical mandate, is greater transparency about the forecast and a greater focus on explaining any departures from the target.

First, the FOMC should not issue a separate "inflation report"- because that would be inconsistent with the spirit of the dual mandate. The only change relative to the Monetary Policy Report and semi-annual testimony would be some explicit commentary on the outcome for inflation relative to the target, and, when inflation is outside the monitoring range, why that occurred and how the Committee viewed the process and timetable for a return to an inflation rate inside the range.

Second, the FOMC forecast should explicitly include whatever inflation measure the target is based upon. Today, the FOMC provides its forecast of the overall inflation rate for the PCE, while many, including myself, believe that the Committee makes its decisions based more on the core measure. If the target is stated in terms of the core measure, it should be included in the FOMC forecast.

Third, since the FOMC controls inflation over the intermediate term, it would be useful if the FOMC forecasts always went out at least $1^{1 / 2}$ to 2 years. The current practice is that the FOMC forecast in late January or early February only extends through the remainder of that year. This should be extended for another year.

Fourth, it might be useful to increase the frequency of FOMC forecasts from twice per year to four times. Just as a picture is worth a thousand words, a forecast can be more revealing than speeches and testimonies.

Fifth, if there is more attention on the forecast, the Committee should fine-tune the process by which they are prepared by the individual Committee members. The forecasts are supposed to be based on "appropriate" monetary policy, but the 
forecasts the staff provides the Committee are often based on a constant nominal funds rate. The staff should help the Committee members in the forecast process by always providing them a forecast based on a policy rule or an "optimal policy" simulation.

\section{AN EXAMPLE OF AN EXPLICIT NUMERICAL INFLATION TARGET}

The FOMC will conduct policy in an effort to achieve maximum sustainable employment and price stability, where the latter is defined as an inflation rate of $1^{1 / 2}$ percent, measured by the core $P C E$ inflation rate. Given that the economy is subject to shocks and business cycles, it will be impossible for the Committee to achieve simultaneously both objectives at each moment in time. The objective for employment is to minimize the variance of employment relative to its maximum sustainable level. The objective for price stability is to achieve an average for the rate of inflation as close as possible to the inflation target over the business cycle.

The inflation target is symmetric, as the Committee recognizes that inflation can be too low as well as too high. Therefore, monetary policy would be directed to raising inflation if it fell below the target and lowering inflation if it rose above the target.

The Committee has intentionally set the target so as to provide some cushion to reduce the likelihood that the economy could encounter deflation or that the federal funds rate could reach the zero nominal bound.

The Committee, in conducting its policy, finds it useful to establish a monitoring range around the inflation target of 1 to 2 percent. Movements within the band represent cyclical variation in the inflation rate that is acceptable to the Committee. Movements outside this range would be of more concern and would be more vigorously countered by monetary policy, with appropriate consideration as to whether the divergences were likely to be temporary or more permanent, without the intervention of policy. 